REVUE DE L'INSTITUT

FRANÇAIS D'HISTOIRE

EN ALLEMAGNE
Revue de I'IFHA

Revue de l'Institut français d'histoire en Allemagne

$6 \mid 2014$

IFHA 6

\title{
Études sur la culture normative nazie
}

Johann Chapoutot

\section{OpenEdition}

Journals

Édition électronique

URL : http://journals.openedition.org/ifha/8065

DOI : $10.4000 /$ ifha. 8065

ISSN : 2198-8943

Éditeur

IFRA - Institut franco-allemand (sciences historiques et sociales)

Édition imprimée

Date de publication : 31 décembre 2014

ISSN : 2190-0078

Référence électronique

Johann Chapoutot, «Études sur la culture normative nazie », Revue de l'IFHA [En ligne], 6 | 2014, mis en ligne le 31 décembre 2014, consulté le 19 avril 2019. URL : http://journals.openedition.org/ifha/8065 ; DOI : 10.4000/ifha.8065

Ce document a été généré automatiquement le 19 avril 2019.

(CIFHA 


\title{
Études sur la culture normative nazie
}

\author{
Johann Chapoutot
}

\section{NOTE DE L'ÉDITEUR}

Travail d'habilitation à diriger des recherches sous la direction de Pascal Ory, université de Paris 1-Panthéon-Sorbonne, soutenu à Paris I le 21 octobre 2013

Face au crime nazi, inouï dans son intensité et son extension, les historiens ont, soit évité la question de la causalité (pourquoi tant de violence ?), soit l'ont posée dans des termes qui privilégiaient:

- Les causalités externes : la crise économique (le choc exogène, terrible, de 1929 qui venait réactiver celui de l'hyperinflation), les mutations sociales (le malaise de la petite bourgeoisie, etc...), les dynamiques de groupe dans les actions de tuerie.

- Les causalités para-humaines (folie, rupture de civilisation, régression dans la barbarie, etc... )

- Une causalité endogène, liée à une supposée idiosyncrasie allemande (celle du «chemin particulier », du Sonderweg).

Peu d'historiens, au fond, ont pris le discours nazi au sérieux. Le nazisme, version allemande du fascisme, serait ainsi une pratique plus qu'une théorie, un corpus d'actes effectués par des hommes aux idées aussi courtes que leurs cheveux. S'il y eut des mots, nazis, ceux-ci sont supposés se limiter à la mise en musique rhétorique d'idées simples et brutales, aussi primaires que l'art oratoire d'un Hitler ou d'un Goebbels.

Certains historiens ont cependant lu avec attention la production nazie : l'Hitler idéologue de Jäckel, mais aussi les anthologies de Wulf et Poliakov ont, dès les années 1960, attiré l'attention sur le fait que le discours nazi n'est pas une logorrhée, mais un logos, structuré, organisé et cohérent. Par ailleurs, la distinction entre discours et pratique reste, dans le cas nazi, largement théorique : ce qui est dit est fait, et ceux qui font disent et justifient sans cesse. 
Le projet de cette HDR était d'appréhender ce que l'on peut appeler l'idéologie, la culture ou la vision du monde (Weltanschauung) nazie. Le corpus étudié est la littérature normative, celle qui énonçait des normes : manuels de combat, fascicules de formation idéologique, presse et cinéma, productions des juristes (manuels, cours, traités, pamphlets, essais...) et des philosophes (quelle éthique pour le nouveau Reich ?), mais aussi des historiens (comment vivaient les ancêtres germaniques?), des médecins, biologistes, raciologues et zoologues... En tout : plus de 80000 pages de sources et plus de 50 films montrant :

- Que les normes héritées, celles du judéo-christianisme, sont néfastes à la race germanique : oui, il est justifié de tuer; non, la monogamie n'est pas un commandement divin, car la nature commande au contraire d'engendrer le maximum d'enfants, etc...

- Qu'il est donc nécessaire de promouvoir de nouvelles normes, en allant les puiser dans le passé de la race germanique : us et coutumes des anciens germains, droit des Grecs et des Romains des origines (qui étaient de race nordique!).

- Qu'il faut donc rendre à la race son authenticité en retrouvant sa nature, i.e. sa naissance. C'est seulement ainsi qu'elle renouera avec la nature et qu'elle survivra, plus puissante, dans un monde d'ennemis.

Ces considérations ne sont pas demeurées circonscrites aux seuls cercles savants : presse, cinéma, enseignement scolaire, formation idéologique montrent que ces nouvelles normes (eugénisme, meurtre, autodéfense raciale, polygamie, etc.) étaient diffusées, car le peuple allemand devait, aux yeux des nazis, être guéri d'un passé millénaire (celui de l'acculturation judéo-chrétienne) par un passé plus ancien encore (celui de la nature germanique). Les acteurs, comme nous le montrent de nombreuses sources privées (journaux intimes, correspondances...) se sont approprié ces normes, qui donnaient sens et justification à leurs actes (tuer un enfant au bord d'une fosse est un acte de bravoure militaire face à l'ennemi biologique juif) et à ce qu'ils voyaient, notamment sur le front de l'Est.

Si, comme l'écrivait Marc Bloch dans la clandestinité, le métier d'historien est de comprendre et non de juger, une telle démarche offre une contribution à la compréhension du phénomène nazi.

Décliné en trois séquences (procréer - combattre - régner), elle offre également, à travers des sources $a$ priori abstraites, une histoire très concrète du IIIème Reich : de ses projets, de ses réalisations, de ses combats et, in fine, de son échec. Le mémoire et les articles qui composent le dossier nous emmènent ainsi, à travers l'étude de la norme, dans l'Allemagne eugéniste et concentrationnaire de 1933, sur le front de l'Est, puis de l'Ouest et, enfin, dans les décombres d'une Allemagne écrasée après un combat que, en bonne logique biologique, les nazis avaient voulu radical. 


\section{AUTEUR}

\section{JOHANN CHAPOUTOT}

(Paris 3 Sorbonne Nouvelle) 